\title{
Application of Hypothetical Development Method in Value Evaluation of Sea Area Use Right- A Case Study of Entertainment Sea Area
}

\author{
Hao Kong ${ }^{1 *}$, Wei Yang ${ }^{2}$, Ricai Peng ${ }^{1}$ and Dengjin $\mathrm{Hu}^{1}$ \\ ${ }^{1}$ Fujian Provincial Key Laboratory of Coast and Island Management Technology, Fujian Institute of Oceanography, 361013 Xiamen, \\ China \\ ${ }^{2}$ Third Institute of Oceanography, Ministry of Natural Resources, 361005 Xiamen, China
}

\begin{abstract}
In recent years, the degree of marketization allocation of marine resources has been increasing in China. The central government has issued a series of laws and regulations to comprehensively promote the bidding, auction and listing of sea area use rights, and local governments have also issued supporting policies for market transfer based on the price assessment of the sea area use right. Among the numerous evaluation methods, the hypothetical development method is to evaluate the developed and undeveloped sea areas as they are completed, which is very suitable for the current situation of sea areas before listing, and has become the most commonly used evaluation method in the field of sea area use right evaluation. In this study, the entertainment sea area in B city is taken as an example, and the sea area price is calculated in detail by using the hypothetical development method. By analyzing the calculation process and results, this paper discusses the application and limitations of the hypothetical development method in the field of sea area price evaluation. It is of positive significance to further improve the price evaluation of the sea areas use right.
\end{abstract}

\section{Introduction}

In recent years, with the acceleration of institutional reform of national resource management, the degree of marketization allocation of marine resources is increasing in China ${ }^{[1]}$. In 2013, the "12th Five-Year Plan of National Oceanic Development in China" required "to carry out sea area value evaluation and promote the implementation of bidding, auction and listing of sea area use rights"; Then, in a series of policy documents, such as "Key Points of Integrated Sea Area Management in 2014", "The 13th Five-Year Plan for National Marine Economic Development" and "Opinions on Paid Use of Sea Areas and Non-resident Islands", it was stated that "the bidding, auction and transfer of sea area use rights should be fully implemented, and the marketization allocation methods should be improved". At the local level, Zhejiang, Hebei, Fujian, Hainan, Shandong and other provinces have issued the management measures of bidding, auction and listing for the sea area use right, in order to standardize the bidding, auction and listing behavior of the sea area use right ${ }^{[2]}$. It can be seen that the marketization allocation of sea areas has become the main methods of sea area transfer, and accurate evaluation of the price of sea area use rights is the basis of implementing marketization allocation.

In October 2020, the Ministry of Natural Resources officially issued the Technical Specification for Sea Area Price Evaluation (HY/T 0299-2020) in order to standardize the price evaluation of sea area use right. The sea area price evaluation methods in the Technical Specification include four methods: income capitalization method, cost approximation method, surplus method (hypothetical development method) and market comparison method. Among them, the surplus method (hypothetical development method) was earlier used by domestic and foreign evaluation industries to evaluate the value of unfinished or undeveloped real estate and land use rights, and accumulated more experience and rich practical experience. In recent years, with the provision of marketization allocation of sea areas, the assumption of "completed state" in developed and undeveloped sea areas is very suitable for the current state before the market transfer of sea areas, and has become the most commonly used evaluation method in the field of sea area use right evaluation. In this study, the entertainment sea area in B city is taken as an example, and the sea area price is calculated in detail by using the hypothetical development method. Through the analysis of the calculation process and results, the application and limitations of hypothetical development method in the field of sea area price evaluation are discussed.

\footnotetext{
*Corresponding author: hayes234@126.com
} 


\section{Research method}

Hypothetical development method refers to a evaluation method of the sea area with the balance of value after the development is completed, based on the normal market price of the sea area project, deducting the normal development cost, profit and interest of the expected investment ${ }^{[3-5]}$. The calculation formula is as follows: $P=V-Z-I$

In which: $p$ is the price of project in the sea area on the benchmark date; $\mathrm{V}$ is the price after the development of the project in the sea area; $\mathrm{Z}$ is the development cost of the project from the base date of evaluation to the completion of development; $\mathrm{I}$ is the profit of the project.

\subsection{Overview of the sea area}

Sea area $\mathrm{S}$ to be evaluated is located in city $\mathrm{B}$, which is used for the construction of marine entertainment and sports casinos. The first-class type of sea area use is for tourism and entertainment, and the second-class type of sea area use is for entertainment sea area; the sea use pattern is entertainment. The project occupies an area of 19.993 hectares. The sea use period is 25 years. The development degree of sea area is vacant, useless sea area facilities and other appurtenances, and the preliminary work has not been carried out, so there is no compensation for sea area stakeholders.

\subsection{Calculation process}

\subsubsection{The price after sea area development (V)}

The price after the sea area development is the yacht wharf price of Project S, and it is assumed that the sea use mode is the best development mode. This paper determines the total price of real estate after development by income method. The sea area occupied by the project is a sea for tourism and entertainment. The sea use period is 25 years. During the construction, only the floating castle and pontoon wharf will be installed, which can be completed in a few days. Therefore, the income generation life is set at 25 years.

1) Calculate annual net income $\left(a_{i}\right)$

Annual net income $=$ annual total rent revenue annual total expenditure

(1) Calculate annual total revenue $\left(Y_{i}\right)$

According to the feasibility study and sea area use demonstration of the project, the entertainment sea area is planned to be divided into three areas, from north to south, namely, "experience area of dynamic water entertainment equipment", "static water interaction area" and "Large-scale water castle area". After the completion of the project, the profit-making model is operated by collecting tickets, and the ticket price is set according to the charging standard of Xiamen Guanyin Mountain Dream Water World Scenic Spot (store 130 yuan/person, group purchase price 110 yuan/person); At the same time, considering the location conditions of B city and Xiamen city, as well as the subsequent competition of similar products, the charging standard of the project operation is set as 80 yuan/person in this evaluation.

The most suitable operation season of the coastal playground in B city is from May 1 to October 8, during which it is affected by typhoons and gale 15 times a year on average, and the affected days are about 3 days each time. Excluding the affected days, the available operating days from May 1 to October 8 are about 113 days.

Combining with the number of domestic and foreign tourists received by a city in recent years, and considering the carrying capacity of the project, it is set that the project can receive 400 tourists on average every day, but with the popularization of the project and the development of surrounding supporting facilities, the number of tourists will gradually increase. According to the calculation of 113 days of operation per year, the project will receive 45,200 tourists in the initial stage of operation. After the operation of the project, the number of tourists will maintain rapid growth with the development of the surrounding areas, and the annual growth rate is set at $5.8 \%$ (in 2018, the number of tourist received by B City increased by $5.8 \%$ year-on-year); From the 6th year to the 10th year, the number of tourists will continue to increase year by year, but the growth rate will decline, set at $2.9 \%$; In the 11 th to 15 th years, the set growth rate will drop to $1.45 \%$; From 16 th year to 25 th year (sea area use permit period), the growth rate will be stable at $0.725 \%$.

The annual income during the operation period of the project can be calculated by multiplying the fare by the number of tourists received each year.

(2) Calculate annual total expenses $\left(\mathrm{C}_{\mathrm{i}}\right)$

The total annual expenses include management costs, Energy and hydropower costs, marketing expenses, financial costs and taxes.

Management costs refer to the costs of necessary management of the entertainment sea area project. This includes labor wages, property fees, office expenses of enterprises, general maintenance fees, daily repair fees, business execution fees, etc. According to the survey results of similar projects by appraisers, the annual management cost here is calculated as $25 \%$ of the annual total revenue.

Energy and hydropower costs are the costs of water, electricity, natural gas, diesel oil and so on. This project is mainly based on offshore facilities, so compared to other water parks, the consumption of water and electricity is relatively small. It is calculated as $3 \%$ of total revenue.

Marketing expenses include sales advertising fees, entrusted marketing agency fees, marketing incentive fees, etc. Here, the annual marketing expenses are calculated according to $5 \%$ of the annual total revenue.

Financial cost is the cost of capital occupied in the process of project operation. The investment profit rate $(18 \%)$ set in this research is set as own capital (there is no interest arising from loans). That is, the profit margin actually includes interest and net profit after deducting the sum of interest. Therefore, in order to avoid double calculation, the interest (financial cost) is set to 0 here, 
and the actual interest is also considered in the profit calculation process.

Taxes refer to relevant taxes and fees paid to the tax authorities in accordance with the regulations. Valueadded tax and various additional taxes are mainly considered here. From May 1, 2016, value-added tax has been implemented in this project, and the general taxpayer's value-added tax rate is $6 \%$. Taking into account other taxes, the comprehensive tax burden is set to $6.723 \%$.

The total cost of each year can be calculated by adding the above costs.

(3) Calculate annual net income $\left(\mathrm{a}_{\mathrm{i}}\right)$

The annual income can be obtained by subtracting the total cost from the total income. The enterprise income tax is calculated at $25 \%$, and the annual net income can be obtained after deducting the enterprise income tax.

\section{2) Discount rate $\left(r_{1}\right)$}

The discount rate of sea area is the ratio used to discount the net income of the sea area into the sea area price. In this study, the sum of the safe interest rate plus the risk adjustment value is used for calculation.

Safe interest rate: the average of the bank time deposit interest rate $(2.75 \%)$ and the three-year national debt interest rate (4\%) in the last three years is $3.375 \%$. Risk-adjusted value: According to the comprehensive analysis of the purpose of the appraisal object, the economic development of the city $\mathrm{B}$, the development status and policies of the tourism industry, and the natural environment, the assessor will score the risk value of the sea project and take the risk-adjusted value $8 \%$. So the discount rate is: $r_{1}=11.375 \%$.

3 ) The price after sea area development (V)

Based on the discount rate of $11.375 \%$, the net income of each year after discounting can be calculated, as shown in Table 1. The net income of each year is discounted and then added together to get the total price after sea area development, which is 1747.4928 ten thousand yuan.

\subsubsection{Development costs (Z)}

Development costs include sea area acquisition fees, compensation fees for sea area use, engineering costs and financial expenses.

Sea area acquisition fees. Sea area $\mathrm{S}$ has not yet established the right to use the sea area, and its acquisition fee mainly considers the upfront costs of related specialties in the sea areas, including marine environmental impact assessment, sea area use demonstration, geological exploration, navigation safety demonstration, etc. The estimation of the upfront work cost standard of each specialty is determined based on the corresponding cost standard. The final estimate is set at 480,000 yuan.

Compensation fees for sea area use. Sea area $S$ is vacant sea area, no sea facilities and other appendages are used, and there is no compensation for sea area stakeholders. Therefore, the sea area compensation fee is set to 0
The engineering cost is the cost of the construction of the project. According to the "Project Engineering Feasibility Study Report", the total engineering cost is 10.705 million yuan.

Financial expenses are the capital occupation cost during the construction period of the project. As mentioned above, this article is set based on own capital (there is no interest arising from loans). The actual interest is also considered in the profit calculation process.

Add up the acquisition fee, sea area compensation fee, engineering cost, and financial expenses to get the total development cost: $\mathrm{Zi}=48+0+10.705=11.035$ million yuan.

\subsubsection{Development profit (I)}

The development profit of the project is based on the price (V) after the development of the sea area, and the sea area development profit is calculated based on the sea area investment return rate comprehensively determined by the sea area use type, development cycle and the social and economic conditions of the location. This project is located in City B and is used for tourism and entertainment. Combined with the average operating profit rate of the tourism industry and the development cycle, referring to the average operating profit rate of tourism enterprises calculated by the "Corporate Performance Evaluation Standard Value" (2019 Edition) [6], $18 \%$ is regarded as the overall development profit of the assessed sea area. $\mathrm{I}=\mathrm{V}^{*} 18 \%=3.145487$ million yuan.

\subsubsection{Price of the sea area $(P)$}

The sea area price after development can be used to deduct the remaining investment costs and the objective development profit, so as to obtain the sea area price of this evaluation.

$$
\mathrm{P}=\mathrm{V}-\mathrm{Z}-\mathrm{I}=3.1444 \text { million yuan }
$$

\section{Results and discussion}

Based on the hypothetical development method, the price of the sea area for S project in City B (the type of sea used is for tourism and entertainment; the sea area is 19.9993 hectares; the duration of the sea area use is 25 years) is 3.1444 million yuan. According to the latest sea area usage fees issued by the Ministry of Finance and the State Oceanic Administration ${ }^{[7]}$, the sea area in the area where the $\mathrm{S}$ project is located is the sixth grade, and the corresponding sea area usage gold standard for open playgrounds is 4,300 yuan per hectare. In the year, the benchmark sea area usage fee calculated according to the gold standard for sea area usage is 2.1499 million yuan (according to the actual management of the marine administrative department, the sea area usage fee set to be collected annually is changed to a one-time collection without discounting). The sea area price calculated by the hypothetical development method in this paper is $46.26 \%$ higher than the sea area price calculated by the gold standard of sea area use. 
From the calculation process, the final sea area assessment results will be affected by many parameters, including the price and sea area development costs after the completion of the sea area development. After the completion of the sea area development, the price and sea area development cost need to be judged based on the project to be constructed in the sea area. Taking the sea for playgrounds in this article as an example, the price after the completion of the development of the sea area is directly affected by the types of amusement facilities and the charging mode after the completion of the project; the cost of the development of the sea area is directly affected by the construction technology, the types of facilities and the number of facilities. Due to the professionalism and particularity of water playground design, it is necessary to judge the type and quantity of amusement facilities based on relevant engineering design reports during the evaluation process. This reflects the two limitations of the hypothetical development method in the current sea area price evaluation field. Details as follows:

(1) In the context of market-oriented transfer of sea area use rights, it is assumed that there is a certain degree of "intention" in the development law. In actual operation, the price evaluation of sea area use rights is mainly applied to the market-based transfer of sea area use rights, and the evaluation results are used as the reserve price for bidding, auction, and listing transfer. Regarding the market-oriented transfer of sea area use rights, in a strict sense, the bidding owner of the sea area is not clear, and the use plan and construction content of the sea area are also unclear. Different sea area users will have different sea area use specifics. Assuming the application of the development method, it is necessary to first clarify the object and use method of the sea area to be assessed after the completion of the development (in this case, it corresponds to the type and type of water amusement facilities, construction technology, etc.); due to the complexity of the sea area development and utilization, it is difficult to be like Land development sets afforestation rate, floor area ratio, etc., to frame the use of non-reclamation projects. Therefore, it can only use the "Project Engineering Feasibility Study Report" of the previous intention unit to assume the value of the sea area after the completion of the development. This undoubtedly has a certain "intentionality."

(2) It is assumed that the most effective utilization principle is applied to calculate the value in the development method, but it is difficult to objectively realize in the sea area assessment. It is assumed that the development method maximizes the value of real estate for future construction in the estimated sea area under the principle of legal and most effective utilization. However, in actual operation, due to the complexity of sea area development and utilization, it is difficult to judge which planning scheme is the most effective use ${ }^{[8]}$. Taking the case of this article as an example, it is difficult for the appraiser to define how to arrange the amusement facilities as the best way during the construction process. In actual operation, the judgment can only be made according to the design plan of the previous intention unit, which also leads to the "intentionality" problem mentioned in the previous limitation.

\section{Conclusion}

The evaluation of the price of sea area use rights is the basis for the implementation of the market-oriented allocation of sea areas. The evaluation results are used as the reserve price for the market transfer of sea area use rights, which is a positive amendment to the gold standard for sea area use. In the case of this article, the sea area price calculated using the hypothetical development method is $46.26 \%$ higher than the sea area price calculated according to the gold standard for sea area use. This has improved the efficiency of sea space utilization to a certain extent and guaranteed the benefits of state-owned resources.

Assuming that the theory of development method is mature, in practice, it is assumed that the development method can be well applied to sea area price evaluation. It has become the most commonly used evaluation method in the field of sea area use right evaluation. It should also be the best choice in sea area use right price evaluation method. However, because the value of an appraisal object is mainly determined by its value constituent factors and value influencing factors, the appraisal of different appraisal objects is obtained by using the same appraisal method even on the same appraisal base date and appraisal purpose. The assessment conclusions may not be the same. Therefore, it is necessary to pay attention to distinguish the characteristics of specific objects in the evaluation process. In addition, considering the complexity of sea area development and utilization, the hypothetical development method often refers to the "Project Engineering Feasibility Study Report" of the previous intention unit in the application process to assume the value of sea area development and calculate the development cost. Strictly speaking, this approach does not fully meet the requirements of market-oriented configuration. This requires the maritime administrative department to make a breakthrough in the system and further improve the market-oriented allocation system and related technical specifications of the sea area.

\section{Acknowledgements}

Project supported by Fujian Province Foundation for Public Welfare Scientific Research Institution (2020R11010011-3), the Natural science funding of Fujian Province (2019J01090).

\section{References}

1. KONG H, HU D J, LUO M X. Ocean Development and Management, (8): 87-91(2017).

2. Luo M X, Tu Z S. Ocean Development and Management, (11): 10-14(2019).

3. SOA. Technical guidelines for sea area assessment (2013). 
4. SOA. Theory and method for sea area assessment (2013).

5. Ministry of Natural Resources. Technical specification for sea area assessment (2020).

6. SASAC. Enterprise performance evaluation standard value, 310-313 (Economic Science Press, 2019)

7. SOA. Sea area usage fee collection standard (2018).

8. Lin J J, Zhang J W. Environment and Sustainable Development, (4): 47-50 (2016). 